\title{
Mantle cell lymphoma mimicking chronic lymphocytic leukemia/small lymphocytic lymphoma on flow cytometry
}

\author{
Kamraan Z. Gill ${ }^{1}$ (D) \\ Received: 18 July 2019 / Accepted: 13 January 2020 / Published online: 18 January 2020 \\ (C) Springer-Verlag GmbH Germany, part of Springer Nature 2020
}

\begin{abstract}
One of the most common applications of clinical flow cytometry is to diagnose chronic lymphocytic leukemia/small lymphocytic lymphoma (CLL/SLL). When classic features are present and correlation with other diagnostic modalities is possible, the distinction of CLL/SLL from other subtypes of B-cell lymphoma is straightforward. However, features deviating from prototypical phenotypes occur not infrequently and can present a diagnostic dilemma. One potential pitfall that has not been well described is mimicry of CLL/SLL by mantle cell lymphoma. A review of flow cytometric data and corresponding clinical, morphologic, and cytogenetic data for 32 cases of mantle cell lymphoma and 67 cases of CLL/SLL was performed to assess the frequency and characteristics of mantle cell lymphoma with features resembling CLL/SLL (i.e., moderate to strong CD23 expression; dim to negative light chain, CD20, CD22, and/or FMC7 expression; and/or dim CD45 expression). Eleven (34\%) mantle cell lymphomas showed one CLL/SLL feature, two (6\%) showed two features, one (3\%) showed three features, and one (3\%) showed five features. Of the markers tested, only dim CD45 expression could reliably exclude all cases of mantle cell lymphoma. Mantle cell lymphoma is capable of mimicking nearly the full spectrum of CLL/SLL features, and evaluation of CD45 intensity can be helpful in challenging cases, observations not previously made. These results suggest that additional markers beyond those traditionally used to diagnose CLL/SLL should be evaluated and results correlated with other diagnostic modalities to ensure accurate classification.
\end{abstract}

Keywords Mantle cell lymphoma $\cdot$ Chronic lymphocytic leukemia $\cdot$ Small lymphocytic lymphoma

\section{Introduction}

Chronic lymphocytic leukemia/small lymphocytic lymphoma (CLL/SLL) is a mature B-cell neoplasm that is generally indolent, usually affects older adults, and is relatively common in western countries, with an incidence of approximately 5 cases per 100,000 population [1]. The diagnosis of CLL/ SLL is made using a combination of morphologic, immunophenotypic, and sometimes genetic features. The degree of peripheral blood or lymph node involvement is also used to distinguish this entity from monoclonal B-cell lymphocytosis (MBL), which does not cause clinical manifestations and is not considered a true lymphoma. The prototypical immunophenotype of CLL/SLL includes expression of CD5,

Kamraan Z. Gill

kgill@ cblpath.com

1 Department of Hematopathology, CBLPath, Inc., 760 Westchester Ave., Rye Brook, NY 10573, USA
CD23, and CD200; dim expression of CD20, CD22, and surface immunoglobulin; and lack of CD10 and FMC7 expression. However, not all cases have these classic features, some being negative for $\mathrm{CD} 5$ or $\mathrm{CD} 23$, positive for FMC7, or showing moderate to strong immunoglobulin expression $[2,3]$.

One of the most common lymphomas considered in the differential diagnosis with CLL/SLL during interpretation of multiparameter flow cytometry (MFC) data is mantle cell lymphoma. Mantle cell lymphoma affects a similar age demographic but is less common and more aggressive than CLL/SLL. Due to significant differences in the biology, clinical course, and management of these two diseases, accurate distinction is essential. Mantle cell lymphoma shares some features with CLL/SLL, including expression of CD5 and pan B-cell markers. However, it typically lacks CD23 and CD200 expression and shows stronger $\mathrm{CD} 20, \mathrm{FMC} 7$, and immunoglobulin expression. A minor subset of cases can show variant immunophenotypes such as absence of CD5 or expression of CD23, CD10, or BCL6 [4-6]. 
When classic immunophenotypic features are seen, it is commonplace for a diagnosis of CLL/SLL to be rendered based solely on MFC data. However, which specific features and how many features must be present to exclude other lymphomas with certainty are not known, and there is considerable variation in clinical practice. Scoring systems such as the Matutes score have been used to facilitate the diagnosis of CLL/SLL based on immunophenotype [7-10]. However, such systems may not have perfect accuracy, and not all of the markers used to generate these scores are universally included in the B-cell panels of different laboratories. The World Health Organization (WHO) 2016 classification has not formally incorporated an immunophenotypic scoring system into diagnostic criteria for CLL/SLL. For these reasons, such systems are often not used in routine clinical practice and interpretation remains subjective.

Due to overlap in immunophenotype and the subjective nature of the interpretation, there remains a risk of misclassification between CLL/SLL and mantle cell lymphoma when MFC data is considered in isolation. When results of immunohistochemical staining for cyclin D1 and SOX11 and/or cytogenetic analysis for CCND1/IGH rearrangement are available, diagnosis or exclusion of mantle cell lymphoma is usually straightforward. However, such results are often unavailable or incomplete at the time of MFC interpretation.

While immunophenotypic variability in mantle cell lymphoma has been described [4-6,11], the frequency and degree to which it overlaps with CLL/SLL during flow cytometric analysis have not been studied in detail. To investigate the frequency and other characteristics of mantle cell lymphoma with features that may mimic CLL/SLL, MFC data was reviewed and correlated with clinical, morphologic, and cytogenetic analyses.

\section{Materials and methods}

\section{Patients and samples}

Case archives from July 2014 through March 2019 were reviewed. MFC results of 41 specimens from 32 patients with mantle cell lymphoma were retrieved. Nineteen of the 41 (46\%) specimens were peripheral blood or bone marrow, and the remaining 22 (54\%) were lymph nodes or extranodal sites. MFC results of 70 specimens from 67 patients with CLL/SLL were also retrieved. Forty-two of the $70(60 \%)$ specimens were blood or marrow, and the remaining 28 (40\%) were lymph nodes or extranodal sites. All cases had a definitive diagnosis of mantle cell lymphoma or CLL/SLL based on the WHO 2016 classification using a combination of MFC, morphology, immunohistochemistry (only for cases with histology), cytogenetics, WBC counts (only for cases of CLL/SLL involving the peripheral blood), and radiologic findings (only for cases of CLL/SLL involving lymph nodes) [1]. When multiple specimens were reviewed for the same patient, data from one representative specimen was chosen for statistical analysis. This yielded 32 unique cases of mantle cell lymphoma and 67 unique cases of CLL/SLL for analysis.

\section{Flow cytometry analysis}

Blood and bone marrow aspirate samples were transported to the laboratory at room temperature in EDTA or sodium heparin tubes. Other tissue specimens were transported in RPMI solution and were kept refrigerated until processing. All specimens were processed with $36 \mathrm{~h}$ of collection. Blood and marrow specimens were first lysed using a solution comprising ammonium chloride, potassium bicarbonate, EDTA, and distilled water. Other tissue specimens were lysed only if contaminated with blood. Following lysis, samples were washed with PBS with $0.1 \%$ sodium azide. Medium containing FBS, penicillin-streptomycin, and RPMI was then added, and specimens were placed in a water bath for $15 \mathrm{~min}$ at 37 degrees $\mathrm{C}$. Specimens were then stained in 8-color tubes and acquired on a Beckman Coulter Navios flow cytometer (Beckman Coulter, Brea, California). See Table 1 for a full list of antibody conjugates, manufacturers, and clones. The panel used for peripheral blood and bone marrow samples included all antibodies listed except FMC7. The panel used for lymph node and extranodal tissue samples included all antibodies listed except CD11b, CD13, CD14, CD33, CD34, CD64, CD117, and HLA-DR.

Analysis of FCS 2.0 data was performed using FCS Express (De Novo Software, Glendale, CA). After exclusion of debris and doublets, neoplastic B cells were gated using a combination of side scatter, CD45, CD19, CD20, CD22, and CD5 depending on the markers available in the specific tube being analyzed. Positive expression of a marker was defined as a fluorescence level exceeding the fluorescence of an internal negative control population, when present, or exceeding the fluorescence of the isotype control when an internal negative control population was not present or could not be reliably isolated. Intensity was judged by visually comparing a neoplastic population to an internal positive control population (e.g., polytypic B cells or T cells) on scatter plots. Expression was considered dim if less than the control, moderate if at the level of the control, and bright if above the control.

\section{Statistical analysis}

Pearson's chi square tests were used to compare frequencies of marker expression between mantle cell lymphoma and CLL/ SLL. 
Table 1 Antibody conjugates, manufacturers, and clones

\begin{tabular}{|c|c|c|}
\hline Antibody & Manufacturer & Clone \\
\hline $\mathrm{CD} 2 \mathrm{APC}$ & Beckman Coulter & $39 \mathrm{C} 1.5$ \\
\hline CD3 ECD & Beckman Coulter & UCHT1 \\
\hline CD4 PE & Beckman Coulter & $13 \mathrm{~B} 8.2$ \\
\hline CD5 APC-Alexa Fluor 750 & Beckman Coulter & BL1a \\
\hline CD7 PC7 & Beckman Coulter & $8 \mathrm{H} 8.1$ \\
\hline CD8 FITC & Beckman Coulter & B9.11 \\
\hline CD10 PC7 & Beckman Coulter & ALB1 \\
\hline CD11b FITC & Beckman Coulter & Bear1 \\
\hline CD13 ECD & Beckman Coulter & 103.44 \\
\hline CD14 PE & Beckman Coulter & RMO52 \\
\hline CD16 ECD & Beckman Coulter & $3 \mathrm{G} 8$ \\
\hline CD19 PC5.5 & Beckman Coulter & J3-119 \\
\hline CD19 APC-Alexa Fluor 750 & Beckman Coulter & $\mathrm{J} 3-119$ \\
\hline CD20 APC & Beckman Coulter & B9E9 (HRC20) \\
\hline CD22 PC7 & Beckman Coulter & SJ10.1H11 \\
\hline CD23 ECD & Beckman Coulter & $9 \mathrm{P} 25$ \\
\hline CD25 PC5.5 & Beckman Coulter & B1.49.9 \\
\hline CD33 APC-Alexa Fluor 750 & Beckman Coulter & D3HL60.251 \\
\hline CD34 APC & Beckman Coulter & 581 \\
\hline $\mathrm{CD} 38 \mathrm{APC}$ & Beckman Coulter & LS198-4-3 \\
\hline CD45-Pacific Blue & Beckman Coulter & $\mathrm{J} 33$ \\
\hline CD56 PC5.5 & Beckman Coulter & N901 (NKH-1) \\
\hline CD64 FITC & Beckman Coulter & 22 \\
\hline CD117 PC5.5 & Beckman Coulter & 104D2D1 \\
\hline CD138 PE & Beckman Coulter & B-A38 \\
\hline FMC7 FITC & Beckman Coulter & FMC7 \\
\hline HLA-DR PC7 & Beckman Coulter & Immu357 \\
\hline Kappa FITC & Beckman Coulter & Polyclonal \\
\hline Lambda PE & Beckman Coulter & Polyclonal \\
\hline 7AAD & Beckon Dickinson & - \\
\hline
\end{tabular}

\section{Matutes score}

Matutes scores were calculated as previously described [7, 8, 12].

\section{Results}

\section{Marker combinations and Matutes scores in mantle cell lymphoma}

See Tables 2 and 3 for a summary of the marker expression data. Seventeen $(53 \%)$ of the 32 cases of mantle cell lymphoma did not show any features considered more typical of CLL/ SLL than mantle cell lymphoma (i.e., moderate to strong CD23 expression; dim to negative light chain, CD20, CD22, and/or FMC7 expression; and/or dim CD45 expression). Eleven $(34 \%)$ cases showed one CLL/SLL feature, two $(6 \%)$ showed two features, one (3\%) showed three features, and one (3\%) showed five features. Seventeen $(53 \%)$ cases had a Matutes scores of 1 , eleven $(34 \%)$ had a score of 2 , three $(9 \%)$ had a score of 3 , and one $(3 \%)$ had a score of 5. Among the cases with only one CLL/SLL feature, eight showed dim CD22 expression, two showed dim surface light chain expression, and one showed moderate to bright CD23 expression. Among the cases with two features, one showed dim surface light chain and $\operatorname{dim}$ CD22 expression, and the other showed moderate to bright CD23 expression and dim CD22 expression. The case with three features showed dim CD20 expression, negative FMC7 expression, and dim CD22 expression. The case with five features showed all features except dim CD45 expression. No significant differences were found in clinical, morphologic, or genetic features between cases with and without features mimicking CLL/SLL. There were no significant differences in marker expression between different sites of involvement.

\section{CD20 expression}

Two $(6 \%)$ of the mantle cell lymphomas and $56(84 \%)$ of the CLL/SLL showed dim CD20 expression $(p<0.05)$, and the remaining cases showed moderate expression (see Fig. 1).

\section{FMC7 expression}

Two (14\%) of the 14 mantle cell lymphomas with FMC7 data available showed expression less than a $30 \%$ cutoff that has been used previously [7]. In contrast, 20 (77\%) of the 26 CLL/ SLL with data available fell below this cutoff $(p<0.05)$.

\section{Light chain expression}

Four (13\%) of the mantle cell lymphomas and 55 (82\%) of the CLL/SLL showed dim surface light chain expression ( $p<0.05$; see Fig. 1). The remaining mantle cell lymphomas showed moderate or bright expression. Most of the remaining CLL/SLL showed moderate expression, and rare cases showed bright expression.

\section{CD23 expression}

While $10(31 \%)$ cases of mantle cell lymphoma showed at least a small proportion of cells (greater than 5\%) positive for CD23, only three (9\%) showed moderate expression by visual analysis of scatter plots. In contrast, all (100\%) of the 67 CLL/SLL showed CD23 expression greater than 5\%, and 56 $(84 \%)$ showed moderate to bright expression $(p<0.05)$. 
Table 2 Mantle cell lymphoma with at least one feature typical of CLL/SLL

\begin{tabular}{|c|c|c|c|c|c|c|c|c|c|c|}
\hline Case & $\begin{array}{l}\mathrm{CD} 20 \\
\operatorname{dim}\end{array}$ & $\begin{array}{l}\text { FMC7 } \\
<30 \%\end{array}$ & $\begin{array}{l}\text { Surface Ig } \\
\text { dim }\end{array}$ & $\begin{array}{l}\text { CD23 moderate to } \\
\text { bright }\end{array}$ & $\begin{array}{l}\mathrm{CD} 22 \\
\operatorname{dim}\end{array}$ & $\begin{array}{l}\text { CD45 } \\
\operatorname{dim}\end{array}$ & $\begin{array}{l}\text { Matutes } \\
\text { score }\end{array}$ & $\begin{array}{l}\text { CCND1/IGH } \\
\text { rearrangement (FISH) }\end{array}$ & $\begin{array}{l}\text { Cyclin D1 } \\
\text { IHC }\end{array}$ & $\begin{array}{l}\text { SOX11 } \\
\text { IHC }\end{array}$ \\
\hline 1 & + & + & + & + & + & - & 5 & + & NA & NA \\
\hline 2 & + & + & - & - & + & - & 3 & NA & + & + \\
\hline 3 & - & NA & - & + & + & - & 3 & + & NA & NA \\
\hline 4 & - & - & + & - & + & - & 3 & + & + & + \\
\hline 5 & - & - & - & - & + & - & 2 & + & + & NA \\
\hline 6 & - & - & - & + & - & - & 2 & + & + & + \\
\hline 7 & - & NA & + & - & NA & - & 2 & + & + & NA \\
\hline 8 & - & NA & + & - & - & - & 2 & NA & + & - \\
\hline 9 & - & NA & - & - & + & - & 2 & + & NA & NA \\
\hline 10 & - & NA & - & - & + & - & 2 & + & NA & NA \\
\hline 11 & - & NA & - & - & + & - & 2 & + & NA & NA \\
\hline 12 & - & NA & - & - & + & - & 2 & + & + & NA \\
\hline 13 & - & NA & - & - & + & - & 2 & + & NA & NA \\
\hline 14 & - & NA & - & - & + & - & 2 & + & NA & NA \\
\hline 15 & - & NA & - & - & + & - & 2 & + & NA & NA \\
\hline
\end{tabular}

${ }^{+}$Feature present

${ }^{-}$Feature not present

$N A$, not assessed

\section{CD22 expression}

Eleven (35\%) of 31 mantle cell lymphomas and $46(70 \%)$ of $66 \mathrm{CLL} / \mathrm{SLL}$ with data available showed dim CD22 expres$\operatorname{sion}(p<0.05)$. The remaining cases showed moderate or rarely bright expression.

\section{CD45 expression}

None of the mantle cell lymphomas and 13 (19\%) of the CLL/ SLL showed dim CD45 expression $(p<0.05)$. The remaining mantle cell lymphomas showed moderate or bright expression, and the remaining CLL/SLL showed moderate expression.

\section{CD5 expression}

Two (6\%) of the mantle cell lymphomas and one (1\%) of the CLL/SLL were CD5 negative (not statistically significant). There was no statistically significant difference in intensity of expression, with $21(66 \%)$ of the mantle cell lymphomas and 38 (57\%) of the CLL/SLL showing dim expression and the remaining cases showing moderate expression.

\section{Discussion}

The data from this study show that mantle cell lymphoma is capable of displaying nearly all of the typical immunophenotypic

Table 3 Marker expression in mantle cell lymphoma and CLL/SLL

\begin{tabular}{llll}
\hline Marker & Mantle cell lymphoma & CLL/SLL & Statistical significance \\
\hline CD20 dim & $2 / 32(6 \%)$ & $56 / 67(84 \%)$ & $p<0.05$ \\
FMC7 <30\% & $2 / 14(14 \%)$ & $20 / 26(77 \%)$ & $p<0.05$ \\
Surface Ig dim & $4 / 32(13 \%)$ & $55 / 67(82 \%)$ & $p<0.05$ \\
CD23 moderate to bright & $3 / 32(9 \%)$ & $56 / 67(84 \%)$ & $p<0.05$ \\
CD22 dim & $11 / 31(35 \%)$ & $46 / 66(70 \%)$ & $p<0.05$ \\
CD45 dim & $0 / 32(0 \%)$ & $13 / 67(19 \%)$ & $p<0.05$ \\
CD5 $\operatorname{dim}$ & $21 / 32(66 \%)$ & $38 / 67(57 \%)$ & NS \\
\hline
\end{tabular}

$N S$, not significant 
Fig. 1 Median fluorescence intensity (MFI) of surface light chain and CD20 expression in mantle cell lymphoma and CLL/ SLL. Data is shown for all cases of mantle cell lymphoma and a representative subset of CLL/

SLL. For each plot, cases are ordered from least to greatest MFI. A small subset of mantle cell lymphomas show dim light chain (A) or CD20 expression (B), while most cases of CLL/SLL exhibit these features a

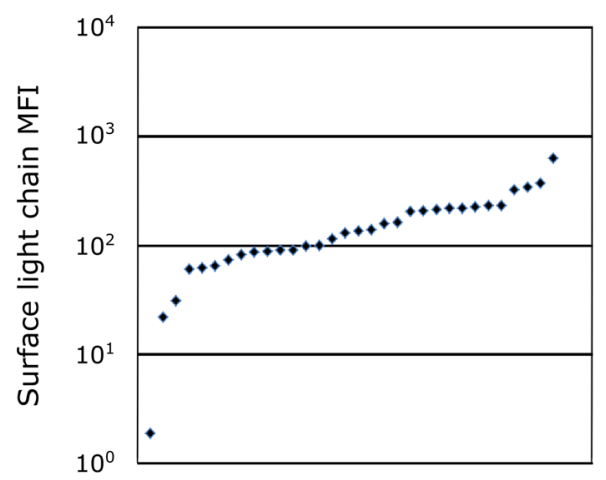

Mantle cell lymphoma

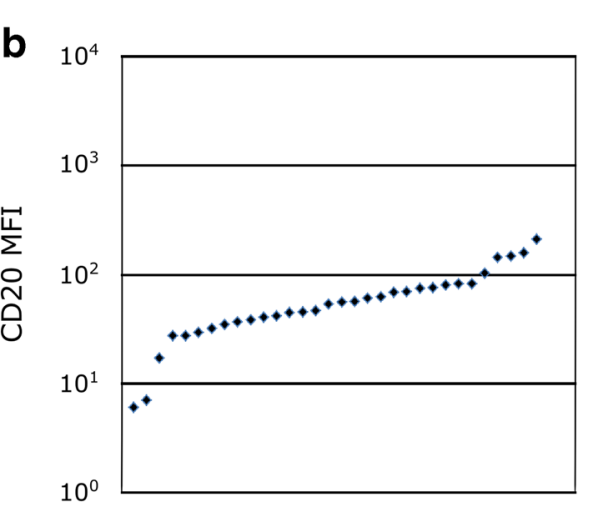

CLL/SLL
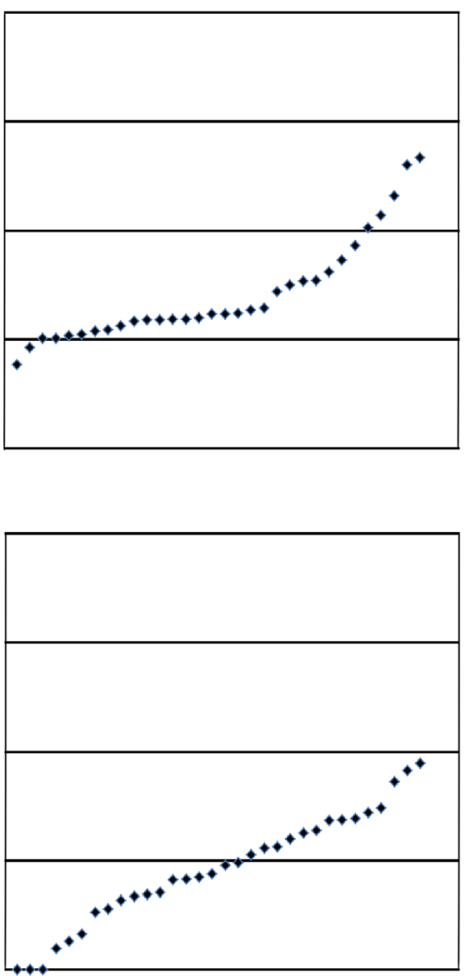

features of CLL/SLL assessed by MFC. While in most of these cases, only one feature is seen, rare cases can mimic nearly the full spectrum of features.

The frequencies of CLL/SLL-like features observed in this study are generally similar to those reported previously, although data on intensity of CD45 expression are very limited [13]. Of the markers evaluated, dim CD45 expression had the greatest specificity (100\%) for CLL/SLL compared with mantle cell lymphoma, an observation not previously made. However, the sensitivity of this marker for CLL/SLL was only 19\%. Dim CD22 expression was the least helpful distinguishing feature, as it was seen in a significant proportion $(35 \%)$ of mantle cell lymphomas and only $77 \%$ of CLL/ SLL. The most sensitive markers for CLL/SLL were dim CD20 (84\%) and moderate to bright CD23 expression $(84 \%)$; these features were seen in $6 \%$ and $9 \%$ of mantle cell lymphomas, respectively.

One particular case in this series showed a remarkable similarity to CLL/SLL, having five different mimicking features. This case is given the highest possible Matutes score of 5, causing a significant risk of misclassification. This finding is in contrast to previous studies suggesting that mantle cell lymphoma does not exceed a Matutes score of $3[7,8]$. These prior studies likely did not report any mantle cell lymphomas with higher scores due to limited numbers of cases evaluated. This case would also be misclassified if diagnosis were based solely on the "required" panel for diagnosis of CLL/SLL recently advocated by the European Research Initiative on CLL (ERIC) and European Society for Clinical Cell Analysis, which includes CD19, CD5, CD20, CD23, kappa, and lambda [14]. However, use of the additional "recommended" markers, not evaluated in the current study, may have been helpful; see below for further discussion of these markers [14]. Interestingly, of the markers assessed, dim CD45 expression was the only feature typical of CLL/SLL not present in this case. The intensity of CD45 expression is not considered by most to be useful in the distinction of CLL/SLL from other lymphomas [7, 8, 12, 14], but these results suggest that it may in fact be diagnostically helpful in challenging cases. Indeed, it is the only marker in this study that could be used to reliably exclude all cases of mantle cell lymphoma. This marker is easily assessed, as it is already present in the B-cell panels of most laboratories. Examination of a larger series of mantle cell lymphomas would be helpful to confirm the utility of this marker.

The immunophenotypic overlap observed in this study raises questions as to whether additional markers may be helpful in distinguishing mantle cell lymphoma and CLL/SLL using MFC. CD200 has emerged in recent years as a robust marker for this purpose, with a very high sensitivity and good specificity in the differential diagnosis with mantle cell lymphoma [15-17]. However, it should be noted that a small subset (approximately 4-8\%) of mantle cell lymphomas do express CD200, and these CD200+ cases may be more likely 
to show other CLL/SLL-like immunophenotypic and morphologic features $[18,19]$. Thus, as with all other markers, CD200 cannot be used in isolation to distinguish mantle cell lymphoma from CLL/SLL. CD200 was not assessed in the current study, as it was not yet validated. Other markers that have been recently recommended to improve the specificity of CLL/SLL diagnosis include CD43, CD79b, CD81, and ROR1 [14]. CD43, CD81, and ROR1 have limited specificity in the differential diagnosis with mantle cell lymphoma [19-22]. CD79b may be more useful for this purpose, but expression tends to correlate with the intensity of CD20 and surface immunoglobulin expression [23].

In summary, one or more features typical of CLL/SLL often occur in mantle cell lymphoma. Novel findings from this study include recognition that mantle cell lymphoma can fully mimic CLL/SLL using traditional markers and that assessment of CD45 intensity can be helpful in such challenging cases. The use of additional newer markers such as CD200 and correlation with immunohistochemistry, routine karyotype, and/or FISH analysis should be performed whenever possible to improve accuracy of classification.

\section{Compliance with ethical standards}

Conflict of interest The author declares no conflict of interest.

\section{References}

1. Weltgesundheitsorganisation (2017) WHO classification of tumours of haematopoietic and lymphoid tissues, Revised 4th edition. International Agency for Research on Cancer, Lyon

2. Criel A, Michaux L, De Wolf-Peeters C (1999) The concept of typical and atypical chronic lymphocytic leukaemia. Leuk Lymphoma 33:3345. https://doi.org/10.3109/10428199909093723

3. Matutes E, Oscier D, Garcia-Marco J, Ellis J, Copplestone A, Gillingham R, Hamblin T, Lens D, Swansbury GJ, Catovsky D (1996) Trisomy 12 defines a group of CLL with atypical morphology: correlation between cytogenetic, clinical and laboratory features in 544 patients. Br J Haematol 92:382-388

4. Gao J, Peterson L, Nelson B, Goolsby C, Chen YH (2009) Immunophenotypic variations in mantle cell lymphoma. Am J Clin Pathol 132:699-706. https://doi.org/10.1309/ AJCPV8LN5ENMZOVY

5. Camacho FI, García JF, Cigudosa JC, Mollejo M, Algara P, RuízBallesteros E, Gonzalvo P, Martín P, Pérez-Seoane C, SánchezGarcía J, Piris MA (2004) Aberrant Bcl6 protein expression in mantle cell lymphoma. Am J Surg Pathol 28:1051-1056

6. Aqil B, Triska G, Frater J, Hassan A, Ruzinova MB, Cashen A, Reese Y, Kreisel F (2018) Immunophenotypic variations in mantle cell lymphoma and their impact on clinical behavior and outcome. Arch Pathol Lab Med 142:1268-1274. https://doi.org/10.5858/arpa.2017-0368-OA

7. Matutes E, Owusu-Ankomah K, Morilla R, Garcia Marco J, Houlihan A, Que TH, Catovsky D (1994) The immunological profile of B-cell disorders and proposal of a scoring system for the diagnosis of CLL. Leukemia 8:1640-1645

8. Moreau EJ, Matutes E, A'Hern RP et al (1997) Improvement of the chronic lymphocytic leukemia scoring system with the monoclonal antibody SN8 (CD79b). Am J Clin Pathol 108:378-382
9. Medd PG, Clark N, Leyden K et al (2011) A novel scoring system combining expression of CD23, CD20, and CD38 with platelet count predicts for the presence of the $\mathrm{t}(11 ; 14)$ translocation of mantle cell lymphoma. Cytometry B Clin Cytom 80:230-237. https:// doi.org/10.1002/cyto.b.20590

10. Köhnke T, Wittmann VK, Bücklein VL, Lichtenegger F, Pasalic Z, Hiddemann W, Spiekermann K, Subklewe M (2017) Diagnosis of CLL revisited: increased specificity by a modified five-marker scoring system including CD200. Br J Haematol 179:480-487. https:// doi.org/10.1111/bjh.14901

11. Nelson BP, Variakojis D, Peterson LC (2002) Leukemic phase of Bcell lymphomas mimicking chronic lymphocytic leukemia and variants at presentation. Mod Pathol Off J U S Can Acad Pathol Inc 15: 1111-1120. https://doi.org/10.1097/01.MP.0000031710.32235.24

12. Matutes E, Polliack A (2000) Morphological and immunophenotypic features of chronic lymphocytic leukemia. Rev Clin Exp Hematol 4:22-47

13. Carulli G, Cannizzo E, Zucca A, Buda G, Orciuolo E, Marini A, Petrini M (2008) CD45 expression in low-grade B-cell nonHodgkin's lymphomas. Leuk Res 32:263-267. https://doi.org/10. 1016/j.leukres.2007.06.002

14. Rawstron AC, Kreuzer K-A, Soosapilla A, Spacek M, Stehlikova O, Gambell P, McIver-Brown N, Villamor N, Psarra K, Arroz M, Milani R, de la Serna J, Cedena MT, Jaksic O, Nomdedeu J, Moreno C, Rigolin GM, Cuneo A, Johansen P, Johnsen HE, Rosenquist R, Niemann CU, Kern W, Westerman D, Trneny M, Mulligan S, Doubek M, Pospisilova S, Hillmen P, Oscier D, Hallek M, Ghia P, Montserrat E (2018) Reproducible diagnosis of chronic lymphocytic leukemia by flow cytometry: an European Research Initiative on CLL (ERIC) \& European Society for Clinical Cell Analysis (ESCCA) Harmonisation project. Cytometry B Clin Cytom 94:121-128. https://doi.org/10.1002/ cyto.b. 21595

15. Alapat D, Coviello-Malle J, Owens R, Qu P, Barlogie B, Shaughnessy JD, Lorsbach RB (2012) Diagnostic usefulness and prognostic impact of CD200 expression in lymphoid malignancies and plasma cell myeloma. Am J Clin Pathol 137:93-100. https:// doi.org/10.1309/AJCP59UORCYZEVQO

16. Mora A, Bosch R, Cuellar C et al (2019) CD200 is a useful marker in the diagnosis of chronic lymphocytic leukemia. Cytometry B Clin Cytom 96:143-148. https://doi.org/10.1002/cyto.b.21722

17. D'Arena G, Vitale C, Rossi G et al (2018) CD200 included in a 4marker modified Matutes score provides optimal sensitivity and specificity for the diagnosis of chronic lymphocytic leukaemia. Hematol Oncol. https://doi.org/10.1002/hon.2510

18. Hu Z, Sun Y, Schlette EJ, Tang G, Li S, Xu J, Yin CC, Young KH, Patel KP, Miranda RN, Goswami M, Wang M, Jorgensen JL, Medeiros LJ, Wang SA (2018) CD200 expression in mantle cell lymphoma identifies a unique subgroup of patients with frequent IGHV mutations, absence of SOX11 expression, and an indolent clinical course. Mod Pathol Off J U S Can Acad Pathol Inc 31:327336. https://doi.org/10.1038/modpathol.2017.135

19. Rawstron AC, de Tute RM, Shingles J, Gorman L, Turner K, Evans PAS, Barrans SL, O'Connor SJM, Burton C, Owen RG, Hillmen P Improving the differential diagnosis of CD5+ Blymphoproliferative disorders. http://learningcenter.ehaweb.org/ eha/2016/21st/133474/andy.rawstron.improving.the.differential. diagnosis.of.cd52B.html?f=m1

20. Barna G, Mihalik R, Timár B, Tömböl J, Csende Z, Sebestyén A, Bödör C, Csernus B, Reiniger L, Peták I, Matolcsy A (2011) ROR1 expression is not a unique marker of CLL. Hematol Oncol 29:1721. https://doi.org/10.1002/hon.948

21. Luo RF, Zhao S, Tibshirani R, Myklebust JH, Sanyal M, Fernandez R, Gratzinger D, Marinelli RJ, Lu ZS, Wong A, Levy R, Levy S, Natkunam Y (2010) CD81 protein is expressed at high levels in normal germinal center B cells and in subtypes of human 
lymphomas. Hum Pathol 41:271-280. https://doi.org/10.1016/j. humpath.2009.07.022

22. Afacan-Öztürk HB, Falay M, Albayrak M et al (2019) CD81 expression in the differential diagnosis of chronic lymphocytic leukemia. Clin Lab 65. https://doi.org/10.7754/Clin.Lab.2018.180802

23. McCarron KF, Hammel JP, Hsi ED (2000) Usefulness of CD79b expression in the diagnosis of B-cell chronic lymphoproliferative disorders. Am J Clin Pathol 113:805-813. https://doi.org/10.1309/ G689-2J36-KCTC-WD5N

Publisher's note Springer Nature remains neutral with regard to jurisdictional claims in published maps and institutional affiliations. 